\title{
The Study of pathway to Increase the International Competence of Zhejiang SMEs
}

\author{
Songyan Zhang \\ School of Economics and Management \\ Zhejiang University of Science and Technology \\ Hangzhou 310023, P. R. China \\ e-mail: syzh201@163.com
}

\begin{abstract}
In the process of economic integration, in order to reduce the market risks and keep the sustainable development, enterprises must improve their competitiveness. Zhejiang SMEs play an important role in economic development of Zhejiang Province. In this paper, with the nine-force analysis model, we analyze systematically the international competitiveness and summarize the following problems faced by Zhejiang SMEs: the financing difficulties, tough export situations, the lack of independent brands, the weakened cost advantages, the lack of enterprise innovative ability and human resources, low levels of corporate management etc. Furthermore, we have put forward the following measures to improve SMEs' competitiveness: promoting new financing ways, easing enterprise financial difficulties; improving export situations, dissolving the risk of foreign trade; improving the quality of products, creating their own brands; promoting the enterprise innovation; enhancing cost management, promoting industrial clusters; paying attention to talent training and improving employment mechanism; improving management system and the efficiency of management.
\end{abstract}

Keywords-small and medium enterprises (SMEs), competitiveness, enhancing approaches

\section{INTRODUCTION}

With the accelerating rate of economic globalization, many companies are exposed to more and more drastic competitions. On one hand, for the sake of survival and development, our companies have to explore the world market, run transnational business, step into the world competition and seek for the foreign resources, technology and space of sales. On the other hand, with the increasing openess of all markets and the increase of mutual trade and investment, even those companies that have never been abroad are now encountering lots of foreign competitors in domestic market. That is to say, companies, whether domestic or abroad, are required to have the ability of competing internationally. Hence, the international competitiveness has become an essential ability for any contemporary enterprises. Besides, in the background of the global financial crisis influences that are penetrating to the real economy gradually and our exporters' survival and development are suffering from challenges, more and more focuses are turning to examine the international competitiveness of enterprises.

Zhejiang SMEs has an absolute advantage in province's national economy. According to the statistics data of Zhejiang Provincial Statistics Bureau, SMEs increase year by year in the proportion of the total number of industrial enterprises in Zhejiang Province. At the same time, the SME has been an important force in Zhejiang Province to promote the development of the national economy, the development of SMEs plays a decisive role in enhancing the economic strength of our province and promoting the sustained and rapid economic development. To some extent, the economic status of Zhejiang SMEs has closely related to its exportoriented development strategy. However, Zhejiang SMEs face a lot of problems in participating international competition. How to follow the trend of globalization and participate in international competition actively? How to prospective grasp the process of internationalization from a strategic point of view and improve international development capacity? These are real problems to be solved for Zhejiang SMEs.

Due to the differences in institutional environment, business normative, market maturity and so on, the empirical findings on the internationalization of SMEs in developed countries can not be fully applied to small and medium enterprises in Zhejiang Province. In this paper, with the nineforce analysis model, we dissect the international competitiveness of Zhejiang SMEs and put forward the corresponding countermeasures.

\section{THE NINE FORCE ANALYSIS MODEL ON THE COMPETITIVENESS OF ENTERPRISES}

Strictly speaking, factors that affect the international competitiveness are very complex, not only including the national and the world political and economic environment, but also the business that enterprises lie in and circumstances of their own. From the related research of domestic and abroad, we can see that although scholars in different countries have different opinions on the expression of the main influencing factors of the international competitiveness, its basic evaluation framework and core are internally consistent. They all examine the factors of international competitiveness from the corporate internal and external influencing, such as external policies and systems, competitive conditions, product, talent, capital, research ect[1].

Considering the characteristics of Zhejiang SMEs, we analyze the competitiveness of enterprises from the explicit competitiveness and internal competitiveness by the effective research of the nine force analysis model. 


\section{A. Explicit competitiveness.}

The explicit competitiveness is the most direct manifestation of the international competitiveness of enterprises, it mainly contains the following assessment indicators:

Brand competitiveness. The brand competitiveness is a comprehensive evaluation of the stability of various brands in the market, the position of each brand in the same industry, the degree of being supported and protected as well as the trend of development. The brand's image and influence play a very important role in the international competition. In a sense, the focus of modern market competition is the competition of enterprise images with brand at the core. The brand competitiveness mainly show in brand value, brand awareness, international advertising and packaging.

Research and development capabilities. Research and development capability is the basic driving force for the development of enterprises, it is also the basic guarantee of the advantage of enterprise competitive. In order to meet the needs of the market and consumers, enterprises must constantly continue to research and develop. R \& D capability mainly refers to the acquisition and utilization capacity of resource; conversion capability of research and development; the ability to marketize the results of research.

Manufacturing capacity. Manufacturing capacity refers to the overall strength of the technology, equipment, plant and personnel of manufacturing product. Manufacturing capacity is reflected in the capacity of production organization to meet market demand, labor productivity, the ability to control manufacturing cost.

Marketing competitiveness. Marketing competitiveness refers the capacity which enterprise is acute to determine market trends, formulate correct market strategy, position the target market accurately, and carry out effective marketing strategies so as to gain high market share and profit margins.

Product competitiveness. The competitiveness of the product is mainly reflected in consumer satisfaction on product performance, price, quality and the comparative advantages of the same kind products.

\section{B. Inherent competitiveness.}

Inherent competitiveness is the comprehension of the strength and potential of the enterprise competition, mainly show in the following aspects:

Resource quality and scale. Resource quality and scale mainly display in human resources, financial resources, material resources and information resources. The essence of enterprise competition is the talent competition, human resources are the core resources of enterprise. Funds and material guarantee the normal operation of the enterprise. At present, the degree of information is one important indicator of the enterprises competitiveness.

Decision-making. Decision-making is an important manifestation of the leader's grasp of enterprise development plan and the effectiveness of organization management capacity. Each successful business has a core leader of Economics and Management Group. In a certain extent, the leader's decision-making ability determines the success or failure of the enterprise.
Ability to execute. The ability to execute refers the openess of the message patency and the effectiveness of decision implementing. It is the coordination of each section of enterprise and each link of project.

Integrating force. The integration of force is the enterprise's ability to establish its overall image and integrate its various resources. In brand communication process, enterprises better integrate resources to establish a better brand image.

\section{THE MAIN PROBLEMS IN THE DEVELOPMENT OF ZHEJIANG} SMES

\section{A. The institution is not perfect.}

External environment has a great impact on the development of enterprises. To some extent, the adverse external environment is able to limit the long-term development of the enterprise directly. These factors include not only legislation and industrial policy, but also the price level, the inflation rate, the interest rate as well as some of the import and export environmental factors. In fact, although Zhejiang Province has introduced many policies and measures to support SMEs in recent years, in accordance with the requirements of the 《SME Promotion Law》, it lacks a comprehensive policy and regulation system to promote the all-round development of SMEs. Systems which government guide and serve for the development of SMEs also need to be further strengthened, and the efforts on the provincial financial support for SMEs should be further increased too[2].

\section{B. Enterprises lack the self-brand.}

In Zhejiang Province, only 10\% enterprises own selfbrand for export. Brand products have a lower share in the international market. Most SMEs accept foreign orders and adopt OEM production. OEM production profits meager and it has no certain value profitability. SME has a high share of market, but it has no stability profit model because of the lack of core brands. Also, there is a poor ability for it to resist risks owing to its excessive dependence on multinational buyers and traders.

Correspondingly, we learn from the investigation of enterprises which has been engaged in international operations that the enterprises whose export volume exceed $50 \%$ have reached $76.7 \%$. This shows that most exports of many companies are non-own brand products despite the great export volume[3]. With the transformation of Zhejiang economy and the requirements to keep sustainable development, enterprise must develop to the upstream and downstream industry of chain, rather than stay in production and processing stages which have the weakest profit. It is very critical for SMEs in international competitiveness.

\section{The cost advantage weakened.}

Production cost advantage has been one of the important factors for Zhejiang SMEs in the international market, it mainly behave labor cost advantage. At present, Zhejiang has been facing challenges that elements resources are being severely constrainted. Competitive advantage of low prices 
gradually weakend, and even lose. In our survey, judging from the average score of the three aspects of the production efficiency, production costs and product quality, the advantage which Zhejiang SMEs think subjectively in the cost of production has become insignificant, and there are no significant advantages in production efficiency and product quality. If we do not pay attention to this problem, it will lead the survival space for SMEs is getting smaller and smaller in the international market.

\section{Business innovation is not strong.}

Most products of Zhejiang SMEs are mainly laborintensive, and the products are low in technological content and added value, thus it is an obvious disadvantage in international competition of similar enterprise.

What we discover from our investigation is that the proportion of expenses spent on research and development takes up the sales is $90.0 \%$ of the surveyed companies invest less than $1 \%$, the percentage of enterprises invest between 3$5 \%$ and more than $5 \%$ are $6.7 \%$ and $3.3 \%$ respectively. While in developed countries, most businesses put at least $5 \%$ of product sales revenue in research and development. Most of the companys' products imitate large enterprises at home and abroad, there is a higher proportion in processing trade and the products with independent intellectual are less than normal[4].

\section{E. Human resources lacking.}

Most of Zhejiang SMEs are private enterprises, family members are often used as management personnel. Decisionmaking mistakes are common occurrences because of their limited energy and knowledge[5]. According to the conclusions of 《the 2011 SME research report》, the low quality of business owners and the difficulty of introducing high-level talents are one of the main reasons for the sustainable development of enterprises. But more important reasons for small businesses are the lack of "senior blue collars" who understand the technical and operational experience. Moreover, there are different views on the capital and the development strategies, and less attention paid on staff training in Zhejiang SMEs. In a certain extent, human resources also limit the development of the enterprise.

\section{PATHWAY TO INCREASE COMPETITIVENESS OF ENTERPRISES}

\section{A. Perfect a legal environment.}

Adopting policies and regulations to support the development of small and medium-sized enterprises is a common practice in many countries and regions in the world. It is also an objective need to give full play to the positive role of SMEs. Zhejiang should learn from the successful experience at home and abroad. Also, it should establish and improve laws and regulations on SMEs. At present, on the basis of the SME Promotion Law, Zhejiang should carry out and improve the various regulations and strengthen local legislations in a planned and systematic way. Moreover, building up better regulations and policy support system gradually for Zhejiang SMEs is necessary. At the same time, Zhejiang should set up appropriate institutions to guide SMEs.

\section{B. Create enterprise own brand.}

The brand is the overall performance of the enterprise competitiveness. If the brand is registered as trademarks, it will be protected by law, this is very favorable for enterprises. Due to the rising production costs, the profits of enterprises rely on OEM production are severely compressed, while some well-known international brands still make use of their brands influence to stand at the top of the industry. Therefore, SMEs should establish brand awareness, locate accurately the position of the brand based on its own strength, develop and design its own brand as well. Although the initial investment in the establishment of the brand is relatively high, from the long-term development plan, the prospects of brand-owned enterprises is much higher than enterprises that do not have a brand. The enterprise which has a good brand is more able to win the trust of consumers, and help to open up the market and increase market share. At the same time, it is also essential to improve the quality of the product, as the quality is fundamental to the foundation and development of a brand, besides, it is also the soul of the brand.

\section{Developingt the industrial clusters.}

Development of industrial clusters is not only just the economic characteristics of Zhejiang, some developed countries and regions also attach great importance to the development of industrial clusters. Japan, Taiwan and Jiangsu are typical examples in this regard. In fact, the core of industrial clusters not only solves the diseconomies of scale, what more important is it is the share and supplement of resources and informations.

In view of this, in order to promote industrial clusters, Zhejiang Province should act as follows at present: Firstly, it should establish the innovation system and enhance the competitiveness of industrial clusters. Secondly, strengthening brand building and building a regional cluster brand are feasible. Thirdly, it is necessary to integrate the resources of various government departments, and guide social resources to the circulation of regional clusters. Fourthly, according to the massive size of the economy and industry characteristics, government should establish the appropriate service agencies, and provide related services to enterprises in the region.

\section{Encourage enterprises to innovate.}

Innovation is the inevitable way for enterprises to gain competitive advantage and improve competitiveness. SMEs should choose the entry point of technological innovation that based on the actual situation. In fact, SMEs do not necessarily put too much funds for the original innovation, but may focus on integrated innovation, absorption and innovation. Also, particular attention should be paid to innovation in existing products and technologies.

Besides the inputs of the enterprise internal $R$ \& $D$ investment, on the other hand, we should make full use of the corporate external R \& D resources. For example, we 
could contribute actively to the formation of industry, academia, research and innovation entities in order to achieve the complementary advantages.

\section{E. Focus on personnel training.}

Talent is the most fundamental guarantee for enterprises to enhance their international competitiveness. Therefore, Zhejiang SMEs must pay attention to the introduction and training of personnel. To some extent, once SMEs have qualified personnel, they have the resources and continued momentum of international development. Consequently, we should not only invest human capital investment to the existing employees, but also introduce directly from external all kinds of much-needed high-level talent. At the same time, enterprises should carry out institutional innovation, establish a personnel system suitable for the growth of talent, set up the concept of meritocracy, and provide a fair, open, and justified competitive environment for talent.

\section{CONCLUSION}

The development of SMEs in Zhejiang is closely linked to the economic development of Zhejiang Province. Therefore, it is a major task faced by Zhejiang SMEs in economic globalization to cultivate and improve the international competitiveness of SMEs. In the fierce international competition, according to the problems faced by Zhejiang SMEs, they should identify the way to enhance the competitiveness of enterprises through the analysis of the competitiveness of enterprises.

In this paper, with the nine-force analysis model, we systematically analyze the international competitiveness and summarize the problems faced by Zhejiang SMEs. Furthermore, we have put forward the measures to improve SMEs competitiveness.

\section{ACKNOWLEDGMENT}

This work was financially supported by the National Natural Science Foundation of China (Grant NO. 11171306) and the Natural Science Foundation of Zhejiang Province (Grant NO. LY12A01024).

\section{REFERENCES}

[1] Mingyang Yu, Zhang mingxin in: On "nine-force model” [J] enterprise research, 2005 (1):40-43.

[2] Ge Gao in: Analysis of small and medium-sized enterprises is how to improve the competitive force $[\mathrm{J}]$. Enterprise technology development, 2009, 28 (4):135-137.

[3] Shuqin Zhang in: Enterprises to improve the competitiveness of key management innovation [J]. Henan Science and Technology, 2009, (6):30-31.

[4] The National Federation. 2011 Research Report of Chinese SMEs [M] Beijing: China Industrial and Commercial Joint Press, 2012.

[5] Jiaxi Wu in: current trend of the development of small and mediumsized enterprises in our province and countermeasures suggested [J]. Zhejiang Industry and Commerce, 2008, (7) :26-29. 